necessaries of life. It is satisfactory to know that the representations of the Italian doctor in the Honolulu newspaper procured for these outcasts some amelioration of their lot, although it procured for himself abuse and illwill. As a frontispiece to the volume there is a woodcut, reproduced from a photograph, of the author surrounded by some of the lepers of Molokai. Other woodcuts are likewise given; but they are chiefly, if not solely, remarkable for their very primitive and inartistic character.

Chemical Lessons.-Lecons de Chimie. Deuxième edition. Par M. Alfred Riche. (Paris: Didot Frères, I869.) LIKE almost all French treatises on elementary science, M. Riche's book is clearly and concisely written, and the illustrations are perfect; but although introducing many of the newest discoveries in the science (perhaps somewhat too pointedly alluded to in the preface), M. Riche does not adopt the important new views lying at the basis of modern chemistry. He still adheres to the old equivalent notation, and therefore refuses to admit the cogency of the proofs which have carried conviction to the minds of almost all other chemists. The short historical introductions under Combustion, the Atmosphere, Dissociation, and the Atomic Theory are of interest to the student, especially an extract (p. 704) from a paper by Dumas on the history of chemical affinity since the time of Barckhausen, read before the Academy of Sciences last year.

H. E, R.

\section{NOTES ON STALACTITES}

THE mineralogist is acquainted with few objects of greater beauty than the stalactitic forms assumed by many minerals. So curious are these natural growths, that I venture to offer a few remarks upon their artificial production.

The dependent clusters which line limestone caverns are formed, as has often been explained, by the following process:- When water containing carbonate of lime oozes through a porous rock, each drop loses water and carbonic acid by evaporation. As water saturated with carbonic acid only retains $0^{\circ} \mathrm{I}$ per cent. of carbonate of lime in solution, it follows that when the evaporation is continued beyond the point of saturation, carbonate of lime will be deposited. Globules of water on the roofs of limestone caverns are always covered with a thin film: this gradually thickens, and a tube is formed. This tube increases in size mainly by the deposition of carbonate of lime from water running over its surface. There are, however, many cavities containing tubes of arragonite in an horizontal position, and even of a curved form. $\mathrm{Mr}$. Wallace has shown $*$ that the growth of such stalactites has been from within outwards, the solution travelling along the self-constructed tube.

The following experiment affords a ready method of studying the somewhat rapid growth of similar forms:Select a flat piece of porous sandstone, or, better, a slice of coke; saturate this with nitric acid. If a globule of mercury three or four millimetres in diameter be allowed to fall on the coke, the surface of the mass will be covered with minute beads of mercury. The nitric acid immediately attacks the under-surface of each sphere, producing an annular ring of nitrate of mercury. A short tube is thus formed, sustaining the metallic globule. As liquids rise in capillary tubes, but do not overflow the orifice, the periphery of the sphere is acted upon by the nitric acid, and lifted higher and higher by the deposited nitrate. The result is a tube of about twenty-five millimetres (one inch) in height, terminated by a minute sphere of mercury.

The cross-section of the stalactite is tubular; often, however, partially filled with interlacing crystalline planes. If nitrate of mercury is deposited more rapidly on one side, a twist is given, and a spiral tube is formed. Often a thin wall on one side predisposes the direction, and a curved stalactite is produced.

It is well to consider briefly the stalactites that appear to have been formed mainly by deposition from water running over their surface. Of this class the siliceous stalactites well repay examination. Silica occurs in stalactite tubes of crystalline silicic anhydride, as in the specimens from Malwa, in Central India.

The chalcedonic form, however, is far more common, and the specimens from Trevascus Mine afford beautiful examples. The tubes are generally about two to three millimetres in diameter, and if a section through the length of the tube be made, the following structure will be easily made out by a hand lens or one inch objective. Firstly, we observe a slender opaque thread with a tube running down its entire length; over this opaque thread there is a covering of chalcedony. Frequently, but not invariably, the junction is marked by a vesicular structure.

To understand this it is necessary to turn to the artificial production of an aqueous solution of silica. By

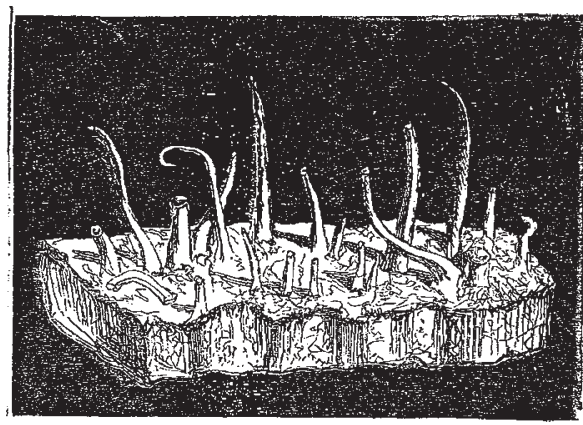

NITRATE OF MIERCURY STALACTITES

bringing together II 2 grammes of silicate of soda, $67^{\circ} 2$ grammes of dry hydrochloric acid, and I litre of water, and dialysing for four days, a solution containing $4^{\circ} 9$ per cent. of silicic anhydride remains upon the dialyser; the chloride of sodium and excess of hydrochloric acid having diffused away. This solution becomes pectous somewhat rapidly, forming a solid jelly which dries in air into a glassy, lustrous hydrate. A solution containing 0.5 per cent. of silicic anhydride remains permanently limpid.

The minutest trace of a soluble carbonate, or a bubble of carbonic acid, causes a solution of silica to gelatinise rapidly. Professor Church has shown the importance of this fact in the formation of siliceous pseudomorphs of corals. By passing water containing 0 I 5 per cent. of silica, dissolved carbonic acid, and air, over the coral, he replaced the carbonate of lime by hydrated silica.

In the Trevascus stalactite under consideration, probably the opaque thread was originally carbonate of lime. The carbonate would have arrested and gelatinised the silica, the covering thus produced affording a colloid septum for the diffusing away of crystalloid salts.

This view is supported by the vesicular junction with the chalcedonic layer, as the escape of carbonic acid would probably have produced bubbles in the yielding jelly. Whether this be so or not, it is easy to convert stalactites of arragonite into siliceous pseudomorphs that present a close resemblance to the natural mineral.

\section{W. ChandleR Roberts}

\section{THE SHARPEY PHYSIOLOGICAL} SCHOLARSHIP

$\mathrm{W}$

$\mathrm{E}$ are most pleased to report that the movement for the establishment of a "Sharpey Physiological Scholarship" at University College, in honour of Prof. Sharpey, is ineeting with all the success that it deserves. Already, by the more or less private efforts of the 